\title{
Experimental Investigation of the Effect of UVA Radiation on the Coronavirus Infective Properties
}

\author{
I. N. Zavestovskaya ${ }^{a, b, *}$, V. A. Guschin ${ }^{c}$, M. A. Nikiforova ${ }^{c}$, A. E. Siniavin ${ }^{c}$, L. I. Russu ${ }^{c}$, \\ E. A. Cheshev ${ }^{a}$, A. L. Koromyslov ${ }^{a}$, I. M. Tupitsyn ${ }^{a}$, A. A. Fronya ${ }^{a, b}$, and M. S. Grigoryeva ${ }^{a, b}$ \\ ${ }^{a}$ Lebedev Physical Institute, Russian Academy of Sciences, Moscow, 119991 Russia \\ ${ }^{b}$ National Research Nuclear University MEPhI (Moscow Engineering Physics Institute), Moscow, 115409 Russia \\ ${ }^{c}$ National Research Center for Epidemiology and Microbiology named after Honorary Academician N.F. Gamaleya, \\ Moscow, 123098 Russia \\ *e-mail: Zavestovskayain@lebedev.ru
}

Received September 5, 2020; revised September 15, 2020; accepted September 16, 2020

\begin{abstract}
The results of experimental studies of the effect of ultraviolet radiation in the UVA wavelength range safe for humans on the $\beta$-coronavirus infective properties are presented. Bovine coronavirus not pathogenic for humans is selected as a prototype of the COVID-19 (SARS-CoV-2) pathogenic agent. LEDs with wavelengths of $371 \mathrm{~nm}$ and $401 \mathrm{~nm}$ are used as a radiation source. It is shown that a dose-dependent decrease in the virus infectious titer is observed for both UVA wavelengths.
\end{abstract}

Keywords: ultraviolet radiation, coronaviruses, bovine coronavirus

DOI: $10.3103 / \mathrm{S} 1068335621070071$

\section{INTRODUCTION}

The pandemic continuing longer than a year, associated with SARS-CoV-2 virus propagation activated studies on the search for not only specific means of preventive maintenance and treatment, but also effective remedy against accumulation and propagation of infectious agents in environment. One of the main ways of virus propagation, along with virus transfer by airborne transmission during a direct contact with infected humans, is human-to-human transmission through contact surfaces followed by transferring to mucous membranes of eyes and upper respiratory airways.

The availability of means that are safe for humans and intended to process contact surfaces to inactivate viruses and bacteria will allow significantly decreasing the number of pathogenic microorganisms and reducing the risk of human-to-human virus transmission.

For the last decade, scientific groups of various countries showed the efficiency of inactivation of some pathogenic agents upon ultraviolet radiation in various wavelength ranges from 220 to $480 \mathrm{~nm}$ [1-10]. The exposure to radiation of the UVC range $(\lambda=200-280 \mathrm{~nm})$ with a maximum at $265 \mathrm{~nm}$ is the most efficient method for inactivating viruses and bacteria, since it is well absorbed by RNA and DNA molecules $[2,5]$. To efficiently suppress pathogenic agents, disinfection should be continuous in facilities of public health; during the period of seasonal infections, disinfection should be made in all rooms of education, industrial enterprises, public catering, and other public accommodations, as well as in public transport. The use of UVC radiation for this purpose is inapplicable, since it is forbidden for application in the presence of people because of ionizing exposure and resulting side effects on mucous membranes and skin (carcinogenesis and others). UVB sources $(\lambda=280-315 \mathrm{~nm})$ and UVA $(\lambda=315-400 \mathrm{~nm})$ are safer for humans; provided irradiation dose constraints, they can also be used in the presence of humans [11].

The studies of recent years on inactivation of pathogenic microorganisms using radiation sources with wavelengths in the UVA range show positive results [5, 12-16], which opens the way to the new technology of continuous inactivation of viruses and bacteria and, to a large extent, makes it possible to prevent global propagation of infectious diseases.

In this paper, we present the results of experimental studies of ultraviolet exposure in the UVA wavelength range safe for humans on infectious properties of coronavirus. As a model virus for studies, bovine coronavirus was chosen, which features a lower degree of pathogenicity in comparison with SARS-CoV-2. Light-emitting diodes with wavelengths of $371 \mathrm{~nm}$ and $401 \mathrm{~nm}$ were used as radiation sources. The irradi- 


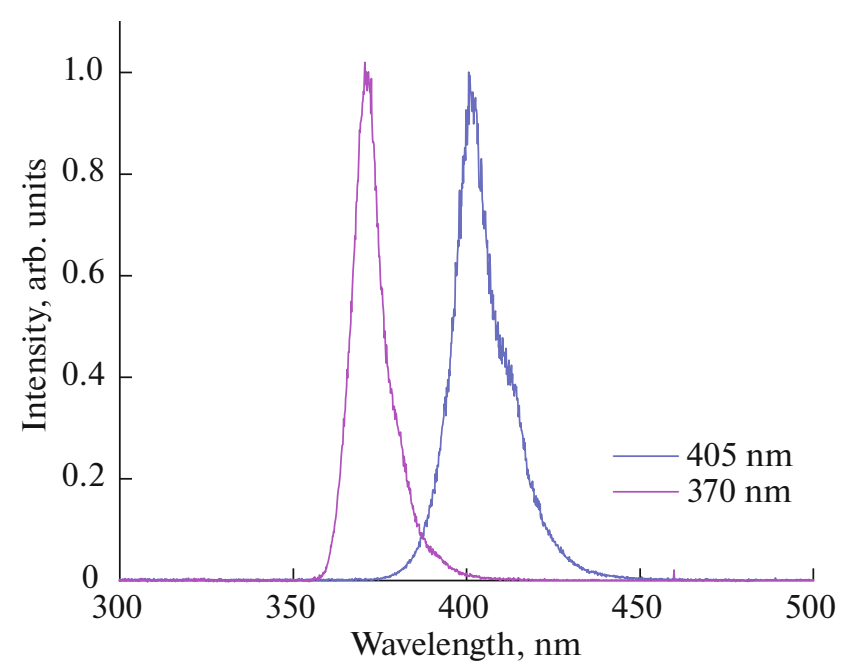

Fig. 1. Emission spectrum of 371-nm and 401-nm UVA sources.

ation dose of bovine coronavirus was varied by irradiation duration. It was shown that a dose-dependent decrease in virus infectious titer is observed for both UV wavelengths.

\section{MATERIALS AND METHODS}

Active studies of antivirus and antibacterial means are in progress at the Gamaleya National Research Center of Epidemiology and Microbiology; a wide spectrum of methods including those for studying bactericidal properties of various substances $[17,18]$ was developed. As viral models, various laboratory virus strains are used in the studies, including animal coronaviruses, as well as other enveloped viruses. The present study of virus-cell systems was performed using developed protocols based on the reference center on coronavirus infections of the Gamaleya Center. Bovine coronavirus was used, which was considered as a model medium for studying SARS-CoV-2 coronavirus [19, 20]. Bovine coronavirus stocks were obtained during acute infection of MDBK (bovine kidney) cells cultivated in a DMEM complete growth medium containing 5\% of embryonic fetal calf serum (FCS), L-glutamin ( $4 \mathrm{mM})$, and a mixture of penicillin/streptomycin antibiotics $\left(100 \mathrm{ME} / \mathrm{mL} ; 100 \mu \mathrm{g} / \mathrm{mL}\right.$ ). The virus titer before irradiation was $10^{5} \mathrm{TCID}_{50} / \mathrm{mL}$. Works with pathogenic microorganisms were regulated by rules of operation with biological agents of pathogenicity groups III-IV (SanPiN (Sanitary-Epidemiological Requirements) 1.3.3118-13).

The efficiency of inactivation of pathogenic biological agents under study on the wavelength and radiation dose was determined according to the developed protocol using semiconductor radiation sources based on commercial light-emitting diodes with wavelengths of $371 \mathrm{~nm}$ and $401 \mathrm{~nm}$. For each radiation source, energy characteristics were measured to provide stability of radiative characteristics. The output power of the light-emitting diode with a wavelength of $371 \mathrm{~nm}$ (UVA range) was $840 \mathrm{~mW}$. The output power of the light-emitting diode with a wavelength of $401 \mathrm{~nm}$ (UVA range) was $750 \mathrm{~mW}$. Figure 1 shows the emission spectra of used light-emitting diodes with wavelengths of $371 \mathrm{~nm}$ and $401 \mathrm{~nm}$.

A virus-containing liquid (VCL) with bovine coronavirus was placed into plate cells (24-well plate) flat-bottom plate with uniform diameter over the well height. Identical VCL amounts $(500 \mu \mathrm{m})$ were poured into wells to provide an identical thickness of the irradiated layer. The plate with filled wells was arranged placed on the blackened surface under the radiation source. The light-emitting diode aperture was at a distance of $4 \mathrm{~cm}$ from the VCL surface. The irradiation dose was determined as the product of the measured power density on the VCL surface in the well and the exposure time.

Plate wells with VCL were marked. Simultaneously four wells with VCL were irradiated. As a control, initial unirradiated material (VCL) was used. The schematic diagram of virus irradiation using light-emitting diodes is shown in Fig. 2.

Table 1 lists the irradiation doses on the surface of a nutritious solution with virus as function of the irradiation time.

After irradiation, the bovine coronavirus infectivity was analyzed using the following technique. Irradiated VCL was collected into a vial, after which tenfold diluted VCL from $10^{-1}$ to $10^{-6}$ was prepared. 


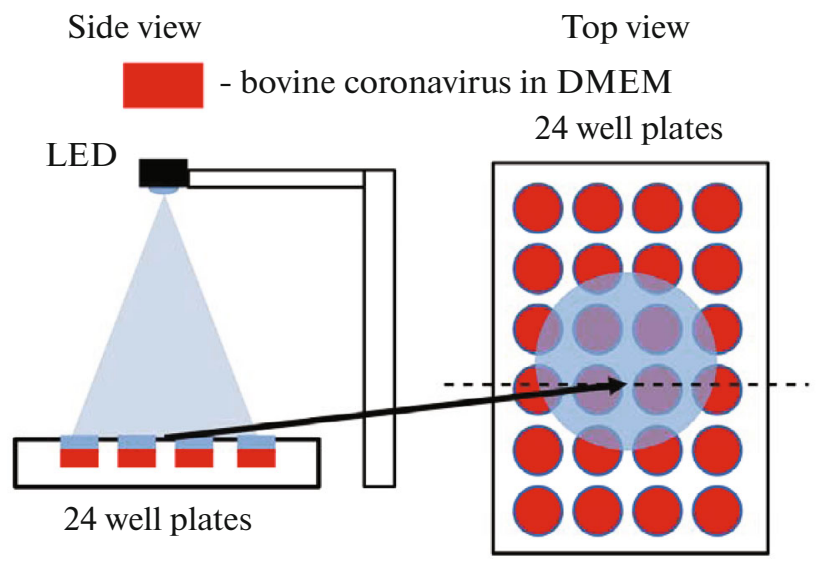

Fig. 2. Schematic diagram of bovine coronavirus irradiation in a $24-w e l l$ plate.

To this end, $0.1 \mathrm{~mL}$ of irradiated VCL is added into a vial with $0.9 \mathrm{~mL}$ of DMEM medium, after which serial dilution to $10^{-6}$ was performed. A day before the experiment, the MDBK cell culture was inoculated into 96-well plates with a concentration of $2.5 \times 10^{4}$ cells per well. VCL titration is performed in four repetitions $(200 \mu \mathrm{L}$ per well) on MDBK cells, for which the growth medium is removed from the plate with a cell monolayer and prepared VCL dilutions are introduced. After that, 96-well plates are incubated for five days at $37^{\circ} \mathrm{C}$ in an atmosphere with $5 \% \mathrm{CO}_{2}$ and $98 \%$ humidity. The virus titer is expressed in $\mathrm{TCID}_{50} / \mathrm{mL}$ based on the virus-induced cytopathic effect.

\section{EXPERIMENTAL RESULTS}

The experimental results are shown in Fig. 3.

The largest decrease in the virus titer is observed when exposing a virus-containing liquid to light-emitting diode with a wavelength of $371 \mathrm{~nm}$ for $40 \mathrm{~min}$. The exposure to both light-emitting diode wavelengths (371 $\mathrm{nm}$ and $401 \mathrm{~nm}$ ) causes a dose-dependent decrease in the infectious virus titer, depending on the exposure time.

The mechanism underlying the inactivation effects of UVA-range radiation has not yet been studied in detail. One of the possible virus damage mechanisms can be the formation of reactive oxygen species. For example, the mechanism of oxidative damage of RNA virus can be implemented as a result of singlet oxygen generation [21, 22]. Reactive oxygen species are presumably formed upon radiation absorption by endogenic sensitizers within the "bovine coronavirus + DMEM" system. The further development of studies implies the determination of the kinetics and mechanism of photoinduced inactivation of nucleic acid, protein, virus lipid molecules upon exposure to radiation in the UVA range, and the determination of the sensitivity of virus and bacterium strains as a function of the inactivation efficiency on the dose and radiation wavelength. This will allow developing an efficient technology for preventing viral and bacterial infection propagation.

Table 1. Irradiation dose on the surface of a nutritious solution with virus as a function of the irradiation time

\begin{tabular}{c|c|c}
\hline UV exposure time & $\begin{array}{c}1-371-\mathrm{nm} \text { (UVA) source. } \\
\text { Irradiation dose }\end{array}$ & $\begin{array}{c}\text { 2-401-nm (UVA) source. } \\
\text { Irradiation dose }\end{array}$ \\
\hline (control) & & $7.5 \mathrm{~J} / \mathrm{cm}^{2}$ \\
$10 \mathrm{~min}$ & $8.4 \mathrm{~J} / \mathrm{cm}^{2}$ & $15 \mathrm{~J} / \mathrm{cm}^{2}$ \\
$20 \mathrm{~min}$ & $16.8 \mathrm{~J} / \mathrm{cm}^{2}$ & $30 \mathrm{~J} / \mathrm{cm}^{2}$ \\
$40 \mathrm{~min}$ & $33.6 \mathrm{~J} / \mathrm{cm}^{2}$ & \\
\hline
\end{tabular}




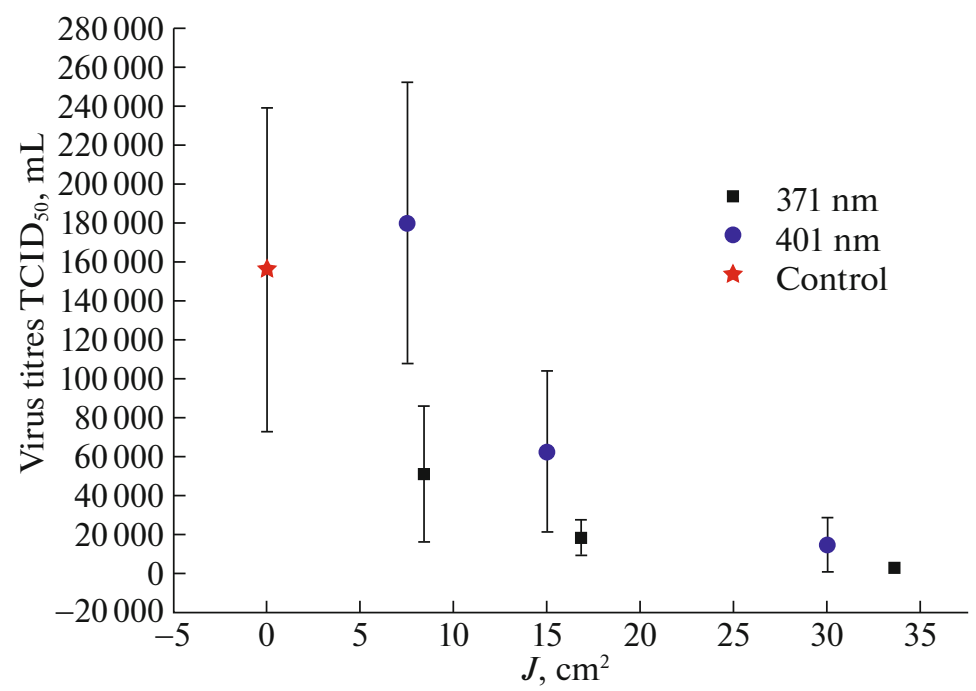

Fig. 3. Dependence of the bovine coronavirus titer on the irradiation dose at wavelengths of 371 and $401 \mathrm{~nm}$.

\section{CONCLUSIONS}

The results of experimental studies of ultraviolet radiation in the UVA wavelength range on coronavirus infectious properties are presented.

Bovine coronavirus was chosen for studies. Light-emitting diodes with wavelengths of $371 \mathrm{~nm}$ and $401 \mathrm{~nm}$ were used as radiation source. It was found that a dose-dependent decrease in the infectious virus titer is observed for both UVA wavelengths.

The results of this study can become a ground for developing a light disinfection technology safe for humans, which can become promisingly universal and undoubtedly the most biocompatible strategy of struggle against pathogenic biological agents, irrespective of whether they are viruses, bacteria, or fungi.

\section{FUNDING}

The reported study was funded by RFBR, project number 20-04-60292.

\section{REFERENCES}

1. Luzzatto-Fegiz, P., Temprano-Coleto, F., Peaudecerf, F.J., Landel, J.R., Zhu, Y., and McMurry, J.A., UVA radiation could be a significant contributor to sunlight inactivation of SARS-CoV-2, bioRxiv, 2020. https://doi.org/10.1101/2020.09.07.286666

2. Gerchman, Y., Mamane, H., Friedman, N., and Mandelboim, M., UV-LED disinfection of coronavirus: wavelength effect, J. Photochem. Photobiol. B: Biol., 2020, vol. 212, p. 112044. https://doi.org/10.1016/j.jphotobiol.2020.112044

3. Tomb, R.M., Maclean, M., Coia, J.E., Graham, E., McDonald, M., Atreya, C.D., MacGregor, S.J., and Anderson, J.G., New proof-of-concept in viral inactivation: virucidal efficacy of $405 \mathrm{~nm}$ light against feline calicivirus as a model for norovirus decontamination, Food Environ. Virol., 2017, vol. 9, no. 2, pp. $159-167$. https://doi.org/10.1007/s12560-016-9275-z

4. Tomb, R.M., Maclean, M., Herron, P.R., Hoskisson, P.A., MacGregor, S.J., and Anderson, J.G., Inactivation of streptomyces phage $\phi \mathrm{C} 31$ by $405 \mathrm{~nm}$ light, Bacteriophage, 2014, vol. 4, no. 3, p. e32129. https://doi.org/10.4161/bact.32129

5. Horton, L., Torres, A.E., Narla, S., Lyons, A.B., Kohli, I., Gelfand, J.M., Ozog, D.M., Hamzavi, I.H., and Lim., H.W., Spectrum of virucidal activity from ultraviolet to infrared radiation, Photochem. Photobiol. Sci., 2020, vol. 19, no. 10, pp. 1262-1270. https://doi.org/10.1039/D0PP00221F

6. Kuzmin, O.V. and Faskhutdinova, N.I., 400-470 nm radiation inactivation of methicillin-resistant staphylococcus aureus, Biomed. Photonics, 2017, vol. 6, no. 4, pp. 37-43.

7. Faskhutdinova, N.I. and Kuzmin, O.V., Photoinactivation of antibiotic-resistant strains of pseudomonas aeruginosa, Med. Fiz., 2017, vol. 76, no. 4, pp. 37-44. 
8. Strakhovskaya, M.G., Meerovich, G.A., Kuskov, A.N., Gonchukov, S.A., and Loschenov, V.B., Photoinactivation of coronaviruses: going along the optical spectrum, Laser Phys. Lett., 2020, vol. 17, no. 9, p. 093001. https://doi.org/10.1088/1612-202X/abab14

9. Kostuchenko, S.V., Tkachev, A.A., and Frolikova, T.N., UV-technologies for disinfection of water, air and surfaces: principles and possibilities, Epidemiol. Vaccinal Prev., 2020, vol. 19, no.5, pp. 112-119. https://doi.org/10.31631/2073-3046-2020-19-5-112-119

10. Smirnov, A.A. and Dovlatov, I.M., Development of a UV-irradiation facility to combat group IV viruses, Vestnik NGIEI, 2020, vol. 115, no. 12, pp. 49-57. https://doi.org/10.24411/2227-9407-2020-10119

11. Egambaram, O.P., Kesavan Pillai, S., and Ray, S.S., Materials science challenges in skin UV protection: a review, Photochem. Photobiol., 2020, vol. 96, no. 4, pp. 779-797. https://doi.org/10.1111/php.13208

12. Darnell, M.E.R., Subbarao, K., Feinstone, S.M., and Taylor, D.R., Inactivation of the coronavirus that induces severe acute respiratory syndrome, SARS-CoV, J. Virol. Methods, 2004, vol. 121, no. 1, pp. 85-91. https://doi.org/10.1016/j.jviromet.2004.06.006

13. Song, K., Mohseni, M., and Taghipour, F., Mechanisms investigation on bacterial inactivation through combinations of UV wavelengths, Water Res., 2019, vol. 163, p. 114875. https://doi.org/10.1016/j.watres.2019.114875

14. Heilingloh, C.S., Aufderhorst, U.W., Schipper, L., Dittmer, U., Witzke, O., Yang, D., Zheng, X., Sutter, K., Trilling, M., Alt, M., Steinmann, E., and Krawczyk, A., Susceptibility of SARS-CoV-2 to UV irradiation, Am. J. Infect. Control, 2020, vol. 48, no. 10, pp. 1273-1275. https://doi.org/10.1016/j.ajic.2020.07.031

15. Nishisaka-Nonaka, R., Mawatari, K., Yamamoto, T., Kojima, M., Shimohata, T., Uebanso, T., Nakahashi, M., Emoto, T., Akutagawa, M., Kinouchi, Y., Wada, T., Okamoto, M., Ito, H., Yoshida, K.I., Daidoji, T., Nakaya, T., and Takahashi, A., Irradiation by ultraviolet light-emitting diodes inactivates influenza a viruses by inhibiting replication and transcription of viral RNA in host cells, J. Photochem. Photobiol. B: Biol., 2018, vol. 189 , pp. $193-200$. https://doi.org/10.1016/j.jphotobiol.2018.10.017

16. De Santis, R., Luca, V., Faggioni, G., Fillo, S., Stefanelli, P., Rezza, G., Lista, F., Rapid inactivation of SARS-CoV-2 with LED irradiation of visible spectrum wavelengths, medRxiv, 2020. https://doi.org/10.1101/2020.06.18.20134577

17. Fursov, M.V., Abdrakhmanova, R.O., Antonova, N.P., Vasina, D.V., Kolchanova, A.D., Bashkina, O.A., Rubalsky, O.V., Samotrueva, M.A., Potapov, V.D., Makarov, V.V., Yudin, S.M., Gintsburg, A.L., Tkachuk, A.P., Gushchin, V.A., and Rubalskii, E.O., Antibiofilm activity of a broad-range recombinant endolysin LysECD7: in vitro and in vivo study, Viruses, 2020, vol. 12, no. 5, p. 545. https://doi.org/10.3390/v12050545

18. Antonova, N.P., Vasina, D.V., Rubalsky, E.O., Fursov, M.V., Savinova, A.S., Grigoriev, I.V., Usachev, E.V., Shevlyagina, N.V., Zhukhovitsky, V.G., Balabanyan, V.U., Potapov, V.D., Aleshkin, A.V., Makarov, V.V., Yudin, S.M., Gintsburg, A.L., Tkachuk, A.P., and Gushchin, V.A., Modulation of endolysin LysECD7 bactericidal activity by different peptide tag fusion, Biomolecules, 2020, vol. 10, no. 3, p. 440. https://doi.org/10.3390/biom10030440

19. Joshi, R.S., Jagdale, S.S., Bansode, S.B., Shankar, S.S., Tellis, M.B., Pandya, V.K., Chugh, A., Giri, A.P., and Kulkarni, M.J., Discovery of potential multi-target-directed ligands by targeting host-specific SARS-CoV-2 structurally conserved main protease, J. Biomol. Struct. Dyn., 2020, pp. 1-16. https://doi.org/10.3390/v12121372

20. Yoshizawa, N., Ishihara, R., Omiya, D., Ishitsuka, M., Hirano, S., and Suzuki, T., Application of a photocatalyst as an inactivator of bovine coronavirus, Viruses, 2020, vol. 12, no. 12, p. 1372. https://doi.org/10.3390/v12121372

21. Sabino, C.P., Ball, A.R., Baptista, M.S., Dai, T., Hamblin, M.R., Ribeiro, M.S., Santos, A.L., Sellera, F.P., Tegos, G.P., and Wainwright, M., Light-based technologies for management of COVID-19 pandemic crisis, J. Photochem. Photobiol. B: Biol., 2020, vol. 212, p. 111999. https://doi.org/10.1016/j.jphotobiol.2020.111999

22. Kohn, T. and Nelson, K.L., Sunlight-mediated inactivation of MS2 coliphage via exogenous singlet oxygen produced by sensitizers in natural waters, Environ. Sci. Technol., 2007, vol. 41, no. 1, pp. 192-197.

https://doi.org/10.1021/es061716i

Translated by A. Kazantsev 